\title{
Dorsal VY Advancement Flap: A Technique for Repair of Simple Syndactyly that Facilitates Direct Closure
}

\author{
HELMY S. ELWAKEEL, M.D.; HASSAN M. KHOLOSY, M.D. and MOHAMED H. ABOUARAB, M.D. \\ The Department of Plastic Surgery Unit, Faculty of Medicine, Alexandria University, Egypt
}

\begin{abstract}
Background: Over the past few decades in a trial to avoid skin grafting and its drawbacks in syndactyly repair, graftless techniques of syndactyly release were advocated with promising success. Two principles typically underly those techniques: Importation of more dorsal hand skin by appropriate flap design and/or finger defatting, this permitted web space reconstruction with direct closure of the fingers. In the present study, a graftless syndactyly repair technique using dorsal VY advancement flap for web space reconstruction combined with defatting of the separated digits is investigated.
\end{abstract}

Patients and Methods: The technique was used in repair of 15 syndactylized web spaces ( 10 simple incomplete \& 5 simple complete syndactyly) in 7 cases, aged between 12-24 month at first surgery. Dorsal VY advancement flap from the hand dorsum just proximal to the neo web space was advanced to resurface the web based on the dorsal intermetacarpal artery perforator. Fingers were separated by straight line incision bisecting the fused digits, this was closed directly after carful finger defatting, resulting in straight line midlateral finger scar.

Results: The technique achieved adequate web space without the need for skin graft in all operated cases. Neither flap necrosis nor web creep was seen in this series with average of 14 months follow up. Midlateral finger scars were cosmetically and functionally accepted. No finger contracture was noticed. Flap donor site (dorsal hand) scar was less forgiving with average of 5 out of 10 on VAS score assessment.

Conclusion: The technique is simple and reliable for repair of simple syndactyly without the need of a skin graft. It is easy to perform in relatively short time.

Key Words: Simple syndactyly - Dorsal V-Y advancement flap - Defatting.

\section{INTRODUCTION}

Syndactyly is a congenital hand anomaly in which there is a fusion of adjacent digits, it is the most common congenital hand anomaly; males are affected twice as females, it is bilateral in half of cases [1-4].

Syndactyly is classified as complete when the fingers are fused along its full length including the nailfold, and incomplete when the fusion spares the fingers distally. Also, it is classified as "simple syndactyly" when fingers are connected by only skin and soft tissue, and "complex syndactyly" in the presence of osseous or cartilaginous connection between adjacent digits [3].

Surgical separation of the syndactylized fingers is nearly indicated for all cases of syndactyly, to improve hand function and appearance. Normal function of fingers requires independent finger location and movement and normal depth of the web space. Therefore, the goal of surgery is to separate of the involved fingers creating a normal or near normal web space [4-6].

Syndactyly release is usually performed around 12 months of age. In most cases this is early enough to allow for normal growth of fingers, and late enough to reduce anesthetic risks and postoperative complications mainly scar contracture, a common drawback of early surgery. However, in cases of syndactyly between fingers of greater size difference such as between the ring and little finger and syndactyly of first webspace waiting too long can result in asymmetric growth of the involved digits with angulation. Surgery in such cases is typically advocated as early as 3 to 6 months of age, as the potential for deformities outweighs the risk in these cases [4-7].

A lot of surgical techniques had been described for syndactyly release [8-25]. All of which must deal with the two issues: Web space reconstruction and finger closure. The early techniques for syndactyly repair reconstructed the web space by a proximally based dorsal flap with a lot of flap designs advocated, and zigzag finger separation to prevent future scar contracture with skin grafting of the separated digits [8-12]. These techniques/ principles are still valuable in current surgical practice especially for complex and complicated 
syndactyly [4]. Skin grafting of the fingers is usually needed in such techniques because for the separated digits a skin deficit/raw area is always present, because the separated digits have a surface area that is roughly $1 / 4$ greater than surface area of syndactylized digits, and because the proximally based dorsal flap used for webspace reconstruction typically extend halfway of the proximal phalanges of the fused digits steeling part of dorsal finger skin for web reconstruction. Drawback of skin grafting included contraction leading to web creep and flexion contractures, pigmentation, and donor site morbidity $[4,7]$.

Over the past four decades in a trial to avoid skin grafting and its drawbacks, methods of syndactyly release without skin grafting were advocated, with promising success especially with simple syndactyly [13-24]. Early published reports of graftless finger closure published utilizied a trilobed dorsal flap modification $[\mathbf{1 3 , 1 4 ]}$ or aggressive finger flaps defatting [15] with acceptable results. Later reports [16-24] utilized an island dorsal flap modification with more proximal location to spare more dorsal fingers skin for primary finger closure. Some of these reports also advocated defatting of the released digits and web space to facilitate closure [17,19]. Defatting alone was viewed as the main factor contributing to direct finger closure by Greuse and Coessens [25].

In the current study the effectiveness of simple VY dorsal advancement flap for web reconstruction in simple syndactyly is investigated to permit graftless fingers closure.

\section{Aim:}

Assessing outcome of dorsal VY advancement flap technique with finger defatting for repair of simple syndactyly with direct closure of the fingers.

\section{PATIENTS AND METHODS}

During the period between February 2015December 2019, a total of 15 syndactyly release operations were performed on 7 patients. Ten webs were incomplete simple syndactyly, and five webs were complete simple syndactyly. The patients age ranged from 12-24 months (mean 17士4.9).

Two out of the five the complete syndactyly webs operated were in a case of left Symbrachydactyly associated with Poland syndrome; the left hand suffered global hypoplasia, with short fingers (brachydactyly) and complete syndactyly of all web spaces. The $1^{\text {st }}$ and $2^{\text {nd }}$ web spaces were operated upon elsewhere, patient was presented for $3^{\text {rd }}$ and $4^{\text {th }}$ web space release (Fig. 1).
Photographic documentation included volar and dorsal hand photographs. Surgery was staged in cases with syndactyly of adjacent digits, with 6 months apart. Before surgery informed consent was taken from parents.

\section{Surgical technique:}

All patients were operated under general anesthesia with tourniquet control; just 30 second of hand elevation instead of complete exsanguination was used, to permit visualization of the digital vessels. A prophylactic IV antibiotic was given after induction of anesthesia (Ceftriaxone $50 \mathrm{mg} / \mathrm{kg}$ as single dose), this was followed by oral antibiotic prophylaxis (Cefalexin 50mg/kg/day in 2 divided doses) starring from $2^{\text {nd }}$ post-operative day and continued for 5 days.

A V-shaped island flap (Fig. 1A) was designed over the dorsum of the hand with its apex starting about $1 \mathrm{~cm}$ proximal to the level of MCP joint and extending distally up to proximal fourth of the proximal phalanx. The flap was mobilized on the subcutaneous pedicle just proximal to MPJ level to capture the distal dorsal metacarpal artery perforator, any other tethering lateral subcutaneous attachment was divided carefully until the flap could be advanced to cover the neo-web space without tension.

Fingers were separated by straight line incision at the dorsal and volar fusion lines (Fig. 1C), a small transverse volar incision at the level of neo webspace was added to the proximal volar incision. Finger were separated from distal to proximal, carefully dividing soft tissue connecting the two digits till the desired level of neo webspace.

Carful trimming of pouting fat along the separated raw fingers surface was done, this was a very cautious step that was carried judiciously under $2.5 \mathrm{X}$ loupe magnification after the neurovascular bundle and dorsal veins identification to prevent any potential hazards.

After completion of dissection the tourniquet was released, bleeding was controlled by compression and judicious use of bipolar cautery, finger circulation was checked. Closure started by first advancing the VY flap to resurface the neoweb space, this was followed by fingers closure from proximal to distal using 5/0 Polyprolene sutures, avoiding undue tension, and accurately opposing skin edges (Fig. 2D). Finger defatting facilitated direct closure of the fingers. In case of undue tension upon finger closure, wound was approximated by sutures leaving $2-3 \mathrm{~mm}$ gap to heal by epithelialization. 
Dressing applied included vaselinated gauze between the fingers and a light pressure bandage.

\section{Follow-up:}

Early follow-up assessed possible early complication including flap vascular compromise or loss, infection, or delayed healing. Sutures were removed 12-14 days postoperative.

Late follow-up period of at least 6 months was employed, follow-up evaluations included assessment of the results and any possible late complications including web creep, flexion contractures, scarring, range of motion and any need for secondary corrective surgery.

Web space depth was compared with normal adjacent webs and/or contralateral digits as appropriate. Parents were asked to grade their satisfaction with the results after 6 months post-operative as either, very satisfied, satisfied, unsatisfied or disappointed. Resultant scars of the midlateral closure of the fingers, and of the dorsal flap donor site were separately assessed using visual analog scale (VAS) by an independent plastic surgeon, a grade form 0 (worst scar) to 10 (best scar) was given at 6 months post-operative evaluation.

\section{RESULTS}

A total of 15 simple syndactyly release operations (10 incomplete \& 5 complete) were performed on 7 patients. The patients age ranged from 12-24

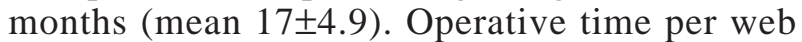

space ranged from 33-43 minutes (mean of 37 \pm 4.1 ). There were no intraoperative complications, no cases of neurovascular injury or flap loss. All fingers were closed directly after careful defatting except for a small (less than $3 \mathrm{~mm}$ ) gaps that were left to heal by epithelialization in distal phalanges of 3 fingers suffering complete syndactyly, all healed eventually without issues.

The follow-up period ranged from 6-31 months (mean 14 \pm 7.8 ). Reconstructed web spaces achieved and maintained good appearance and depth without web creep over the follow-up period in all cases.

Reconstructed fingers achieved range of motion comparable to normal fingers. Only the Symbrachydactyly case (Fig. 1), although fingers were adequately separated, but fingers shape and function were compromised because of the other associated finger anomalies.

The midlateral fingers scars were inconspicuous in all cases at 6 months post-operative. Its grading using VAS score by a plastic surgeon uninvolved in the study yielded a score of 7-9 out of 10 (average 8 ). The VAS score grading of dorsal hand scar (flap donor site) yielded inferior results, with score of 4-7 out of 10 (average 5.35).

Parents were either satisfied (4 cases) or very satisfied ( 3 cases) with the results. Study results are summarized in Table (1). Figs. (1-3) show the operative steps and late postoperative results.

Table (1): Summery of patients demographic data and results.

\begin{tabular}{|c|c|c|c|c|c|}
\hline $\begin{array}{l}\text { Serial } \\
\text { No. }\end{array}$ & $\begin{array}{l}\text { Age at first } \\
\text { surgery }\end{array}$ & Type of syndactyly \& web space involved & Follow-up & $\begin{array}{c}(\text { VAS }) \\
\text { finger scars }\end{array}$ & $\begin{array}{l}\text { (VAS) dorsal } \\
\text { hand scar }\end{array}$ \\
\hline 1 & 24 months & Simple incomplete - right $2^{\text {nd }}$ web space & 6 months & 8 & 6 \\
\hline 2 & 14 months & Left hand Symbrachydactyly. & 12 months & 7.5 & 4 \\
\hline 3 & 23 months & $\begin{array}{l}\text { Simple complete syndactyly }-3^{\text {rd }} \& 4^{\text {th }} \text { web. } \\
\text { Right hand - Simple incomplete }-3^{\text {rd }} \text { web } \\
\text { Left hand - Simple incomplete }-3^{\text {rd }} \text { web }\end{array}$ & 31 months & 9 & 7 \\
\hline 4 & 18 months & $\begin{array}{l}\text { Right hand - Simple incomplete }-3^{\text {rd }} \& 4^{\text {th }} \text { web } \\
\text { Left hand - Simple incomplete }-3^{\text {rd }} \text { web } \& \\
\text { simple complete }-4^{\text {th }} \text { web }\end{array}$ & 15 months & 8.5 & 5.5 \\
\hline 5 & 13 months & Left hand - Simple incomplete $-3^{\text {rd }} \& 4^{\text {th }}$ web & 12 months & 8.5 & 6 \\
\hline 6 & 12 months & Right hand - Simple complete $-3^{\text {rd }} \& 4^{\text {th }}$ web & 13 months & 7 & 5 \\
\hline 7 & 14 months & Left hand - Simple incomplete $-3^{\text {rd }} \& 4^{\text {th }}$ web & 12 months & 8 & 4 \\
\hline
\end{tabular}




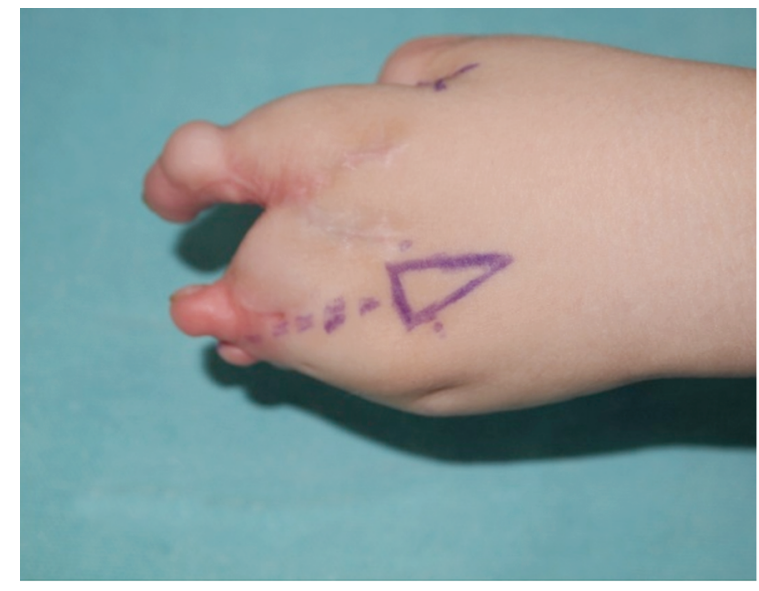

(A)

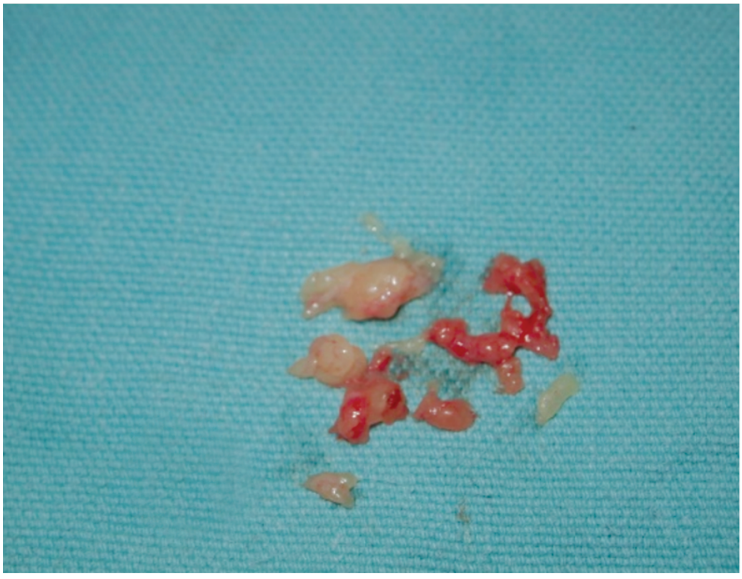

(C)

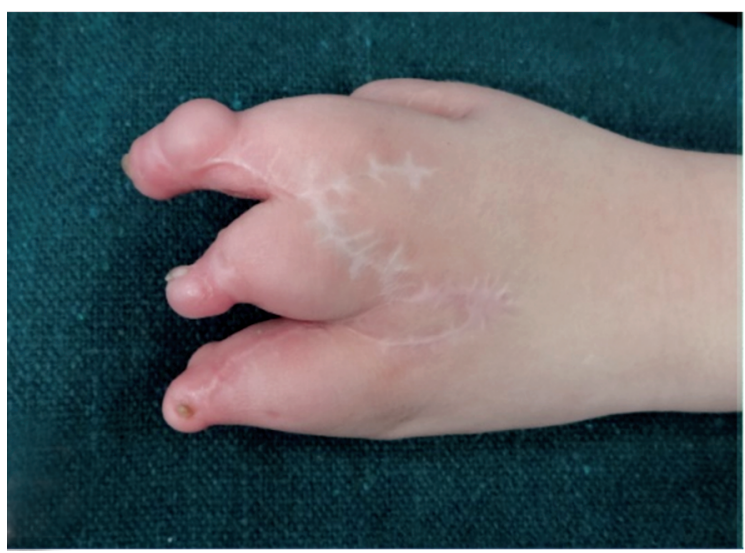

(E)

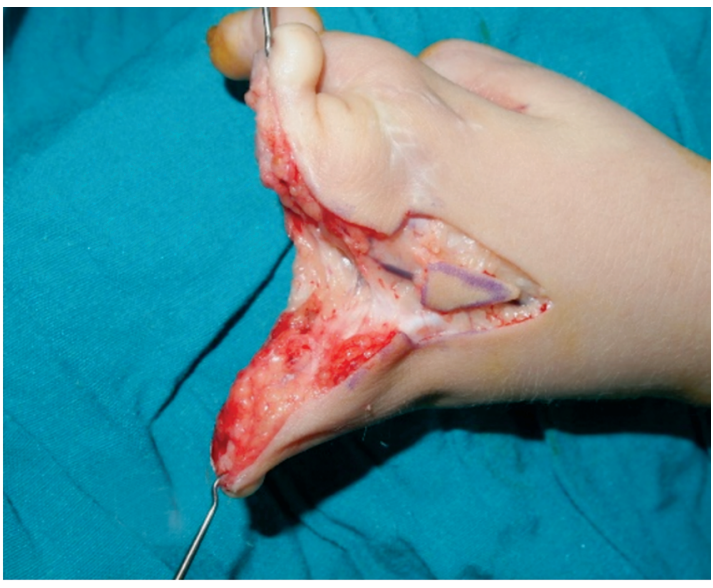

(B)

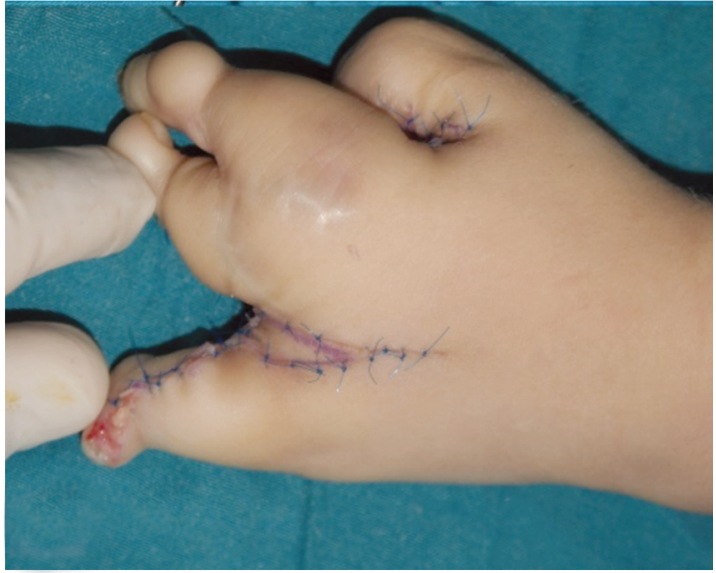

(D)

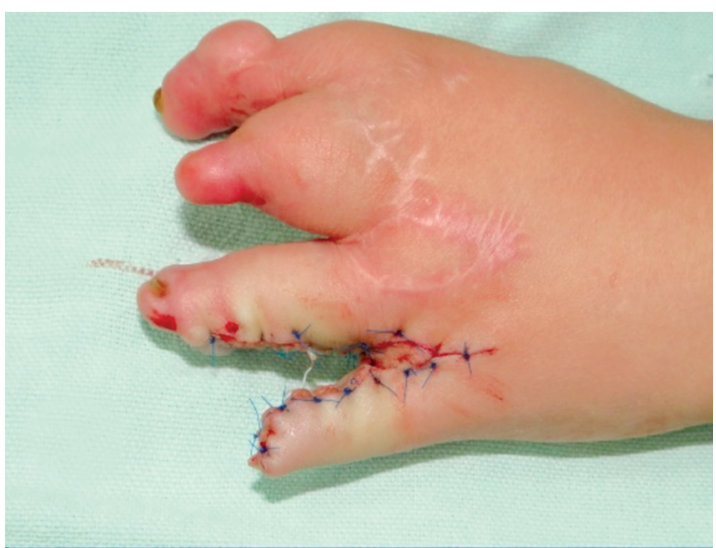

(F)

Fig. (1): Left symbrachydactyly, $1^{\text {st }} \& 2^{\text {nd }}$ web was previously operated elsewhere, and patient presented for $3^{\text {rd }}$ and $4^{\text {th }}$ web release (A). VY flap design on dorsum of hand for $3^{\text {rd }}$ web release. (B) After $3^{\text {rd }}$ web release and flap dissection. (C) Excised fat from fingers (defatting). (D) VY flap inset to create neo-web and direct fingers closure. (E) 6-month results of released $3^{\text {rd }}$ web. (F) Immediate post-operative photo of $4^{\text {th }}$ web release 6 month after $3^{\text {rd }}$ web release. 


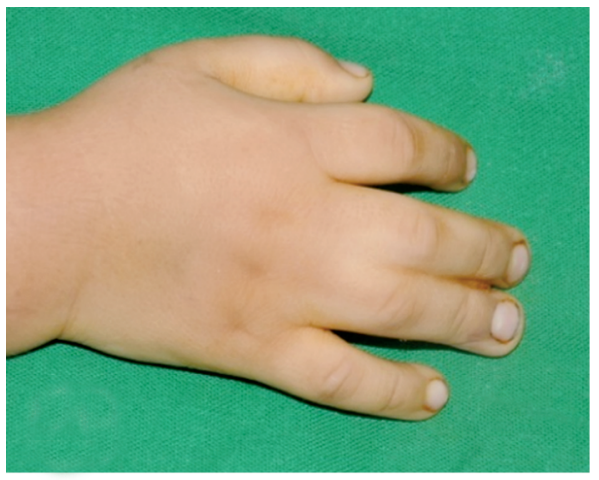

(A)

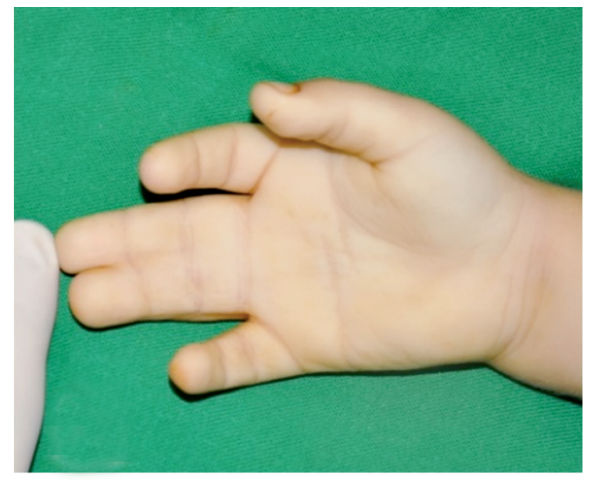

(B)

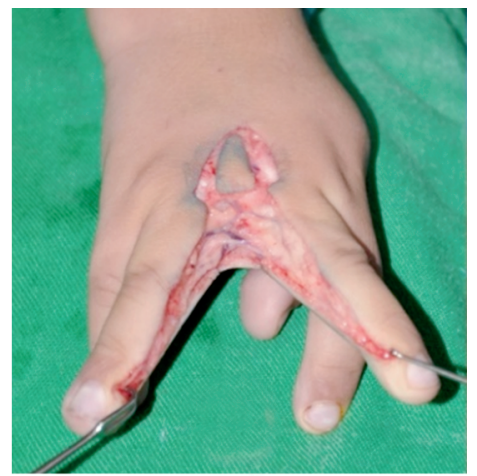

(C)

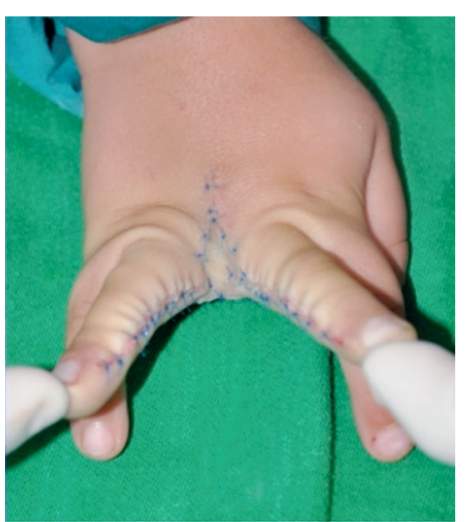

(D)

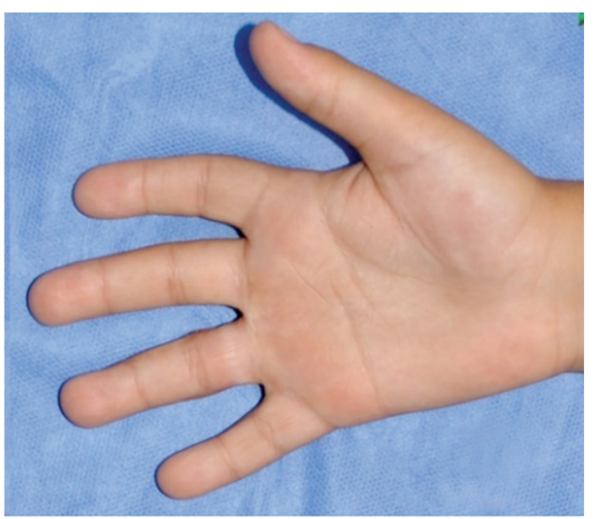

(E)

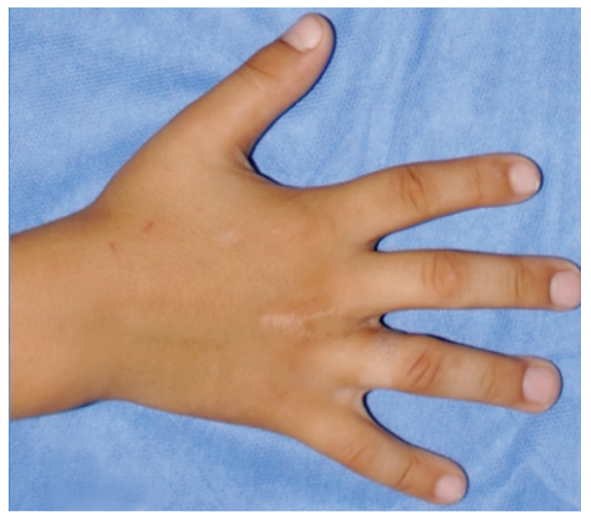

(F)

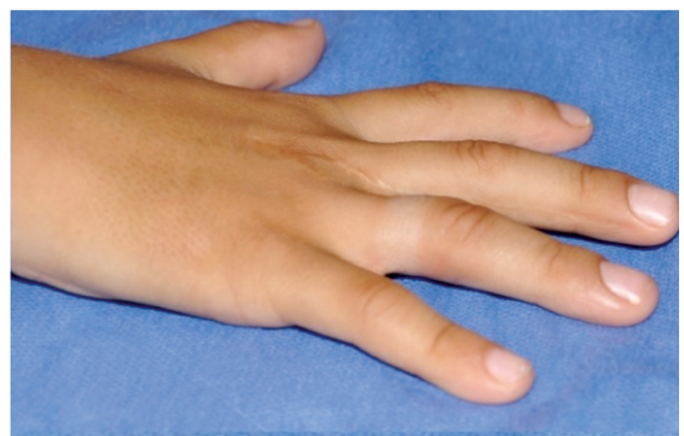

(G)

Fig. (2): Right incomplete $3^{\text {rd }}$ web syndactyly. (A: Dorsal view, B: Volar view) preoperative. (C) Intraoperative view after flap dissection and fingers release using midlateral incision. (D) After flap inset and direct finger closure. (E\&F) 31 months postoperative results showing adequate web space, dorsal hand scar is of average quality. (G) Acceptable midlateral scar. 


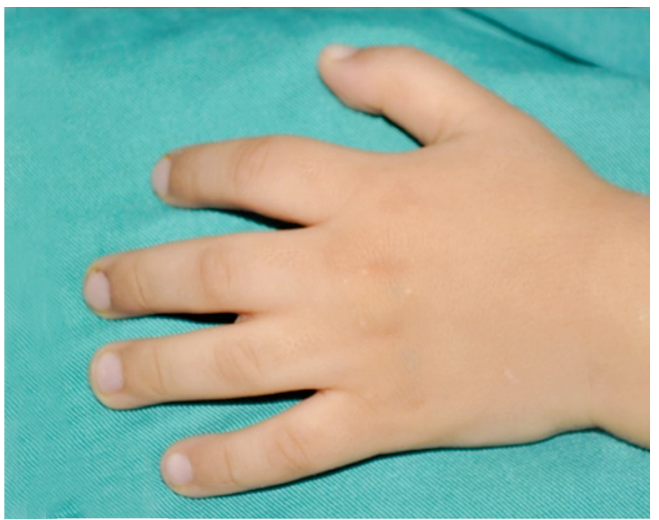

(A)

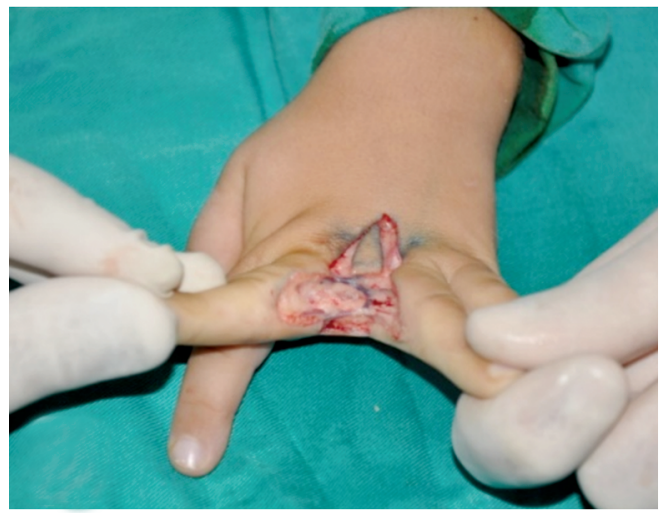

(C)

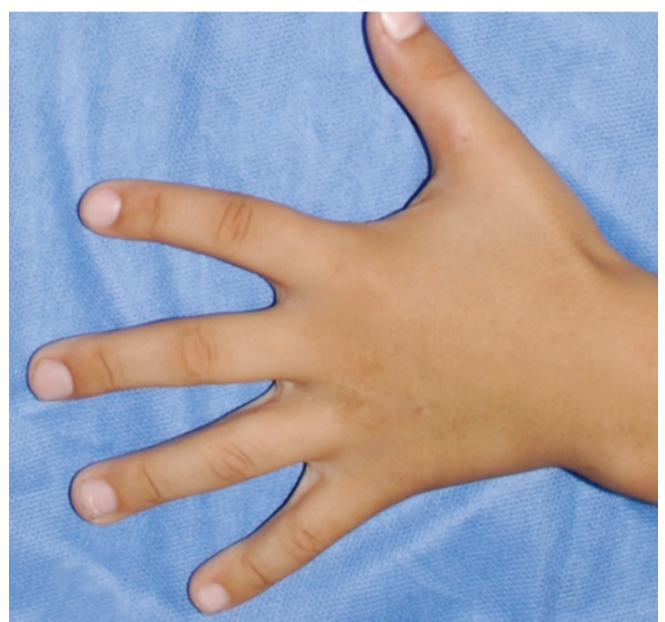

(E)

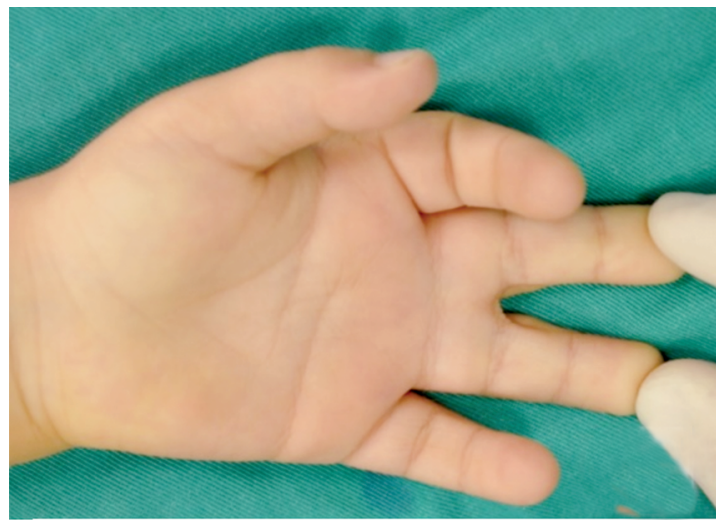

(B)

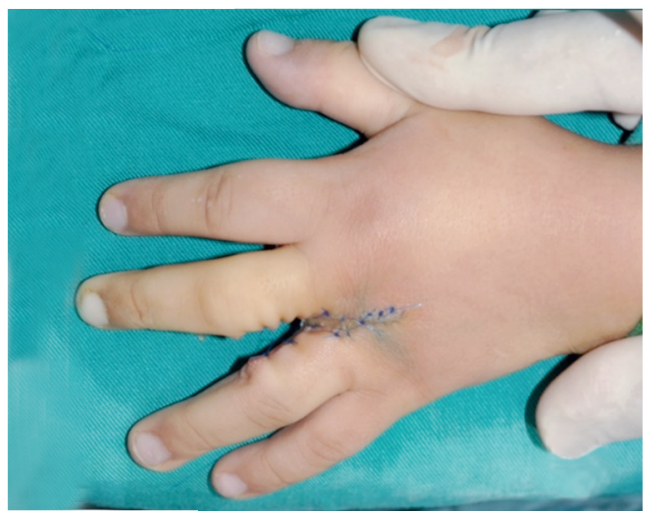

(D)

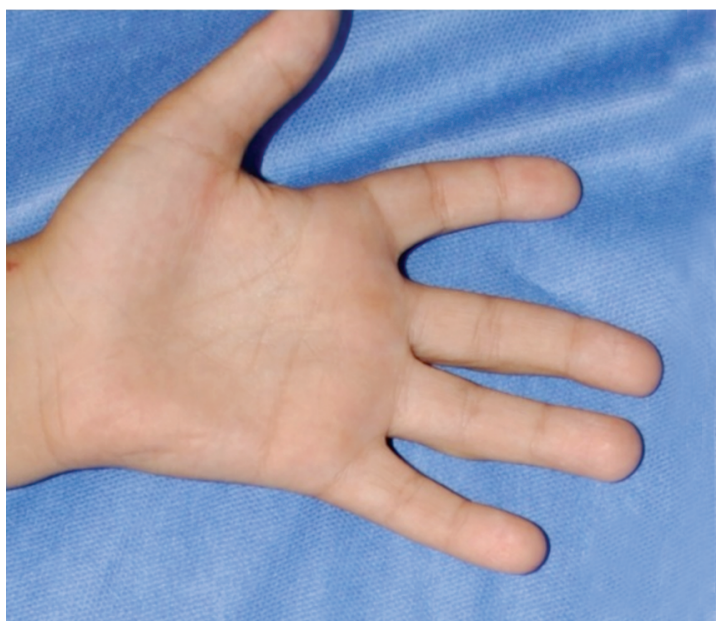

(F)

Fig. (3): Left incomplete $3^{\text {rd }}$ web syndactyly (A: Dorsal view, B: Volar view) preoperative. (C) Intraoperative view after flap dissection and fingers release using midlateral incision. (D) After flap inset and direct finger closure. (E\&F) 31-month postoperative results showing adequate web space and acceptable scaring.

\section{DISCUSSION}

Over the past few decades, aiming at avoiding skin grafting in syndactyly repair, many authors described a dorsal flap designs that steal more dorsal hand skin for webspace reconstruction and so sparing more dorsal finger skin to permit direct finger closure thus avoiding skin grafts. Modified dorsal trilobed flap described by Niranjan and de Carpentier, 1990 [13] was the first report of graftfree syndactyly repair. Perforator-based island dorsal flap for web reconstruction was first reported by Sherif, 1998 [16]. He used an island dorsal VY advancement flap (based on dorsal metacarpal 
artery perforator) for syndactyly release without skin grafts. This landmark paper opened the door for numerous subsequent publications [16-24] including this series, which reported similar or modified techniques of island dorsal flap designs for neo-web creation with promising success.

In the present study, a combination of dorsal VY advancement flap and straight midlatral finger closure after defatting was adopted for release of simple syndactyly with good functional and acceptable cosmetic results. Web spaces were adequate at 6 months follow-up period in all cases. Designing the V shaped flap over the hand dorsum with the flap tip located $1 \mathrm{~cm}$ proximal to the MCP joint level and its distal base leveled with the proximal $1 / 4$ of the proximal phalanx, spared most of dorsal finger skin to facilitate direct finger closure next to the created neoweb. Adequate flap dissection leaving only cuff of subcutaneous tissue between the metacarpal heads to capture the perforator from the dorsal intermetacarpal artery, allowed easy flap advancement to reconstruct the web space $[\mathbf{1 6 , 2 6}]$. Flap blood supply is reliable and consistent even in rare occasions of absence of dorsal metacarpal vessels, the flap perforator would originate from the volar carpal arch [26].

Sharma et al., 2009 [14] used similar dorsal VY flap technique for repair of 14 web space syndactyly and reported satisfactory results in all cases, a result comparable to the current series. In Sharma et al., report the $\mathrm{V}$ shaped flap was centered more distally near the new web. We think this would compromise the ability of direct closure of the proximal fingers next to the flap, as it incorporates more skin from the dorsal aspects of the proximal fingers rather than the distal dorsal hand skin. The more proximal flap location reported by Sherif [16] would spare more dorsal finger skin at the base of the proximal phalanges to be recruited for direct closure of the separated fingers without skin grafting. This design was adopted in this study with the flap apex located approximately $1 \mathrm{~cm}$ proximal to MCPJ line, and distal flap base limit was the proximal $1 / 4$ of the proximal phalanx.

Probably an interesting aspect of the current series that was originally adopted by Sharma et al., [14] is the straight-line finger separation with final harmless midlateral finger scar. The midlateral finger incision/scar pattern is well known to be safe scar for other elective hand surgery procedures [4]. In the current series even in cases in whom a little 2-3mm gaps over distal phalanges, were left for healing by epithelization, the midlateral scar was accepted both cosmetically and functionally. In term of cosmesis, fingers scars were more hidden, and probably more forgiving compared to zigzag closure. Avoidance of the mosaic pattern of zigzag incisions, that incorporate dorsal skin to the volar fingers, and vice versa is another advantage of midlateral closure, no finger contracture was reported in this series.

In the current study, all operated web spaces were of simple syndactyly type, most of them (10 out of 15 webs) were incomplete syndactyly. The authors agree with many of literature reports $[19,21,23,28]$ of such graftless syndactyly release being inappropriate in cases of complex syndactyly and would be more challenging in cases of complete simple syndactyly especially of two adjacent webs. In the later cases more aggressive defatting was needed in this series and in 3 fingers out of 5 web cases of the complete syndactyly, direct midlateral finger closure was not achievable, and $2-3 \mathrm{~mm}$ gap was left for epithelization over distal phalanges. We think it may be successful to repair the 1 st of multiple adjacent fingers of complete and/or complex syndactyly using this technique, but next web space would be extremely challenging with a relatively unacceptable skin gap left for epithelization that would even entails the base of the finger next to the created web.

The dorsal hand flap donor site scar is significant drawback of graft free syndactyly repair techniques [27]. In this series, scaring on dorsum of the hand was unsightly (average of 5 out of 10 VAS score). The midlateral finger scars were more forgiven (average of was 8 out of 10 VAS score).

Vickers and Donnelly [15] used the traditional dorsal rectangular flap design and zigzag finger incision in a series of 31 syndactyly release operations. Only aggressive finger flaps defatting allowed direct finger closure and avoided the need for skin graft in all cases, but small raw gapes were left for epithelization between finger flaps just next to reconstructed web and on distal phalanx in some cases. They reported a relatively high (23\%) rate of web creep and reoperation. A recent systemic review by Sullivan and Adkinson [28] compared the overall outcome and complications among simple syndactyly repair using skin graft and graftless dorsal metacarpal advancement flap revealed higher incidence of web creep in the skin graft group. This would emphasize the value of the technique of dorsal island advancement flap modification to spare finger skin for direct finger closure next to the created web, to avoid web creep. 


\section{Conclusion:}

Repair of simple syndactyly using this technique is easy, reliable, and time saving operation. Flap design is straight forward with consistent vascular supply.

Dorsal hand scar was not aesthetically appealing in most of cases, a significant disadvantage of this technique that should be considered while deciding which technique would be selected for every individual case.

\section{REFERENCES}

1- Goldfarb C.A.: Congenital hand differences. J. Hand. Surg. Am., 34 (7): 1351-1356, 2009.

2- Kozin S.H. and Zlotolow D.A.: Common pediatric congenital conditions of the hand. Plast. Reconstr. Surg., 136 (2): 241e-257e, 2015.

3- Malik S.: Syndactyly: Phenotypes, genetics, and current classification. Eur. J. Hum. Genet., 20 (8): 817-824, 2012.

4- Green D.P., Hotchkiss R.N., Pederson W.C. and Wolfe S.W.: Green's Operative Hand Surgery. Vol. 2. $7^{\text {th }}$ ed. Philadelphia: Elsevier PA, pp. 1217-1232, 2017.

5- Netscher D.T. and Baumholtz M.A.: Treatment of congenital upper extremity problems. Plast. Reconstr. Surg., 119 (5): 101e-129e, 2007.

6- Oda T., Pushman A.G. and Chung K.C.: Treatment of common congenital hand conditions. Plast. Reconstr. Surg., 126 (3): 121e-133e, 2010.

7- Lumenta D.B., Kitzinger H.B., Beck H. and Frey M.: Long-term outcomes of web creep, scar quality, and function after simple syndactyly surgical treatment. J. Hand Surg. Am., 35 (8): 1323-1329, 2010.

8- Cronin T.D.: Syndactylism: Results of zig-zag incision to prevent postoperative contracture. Plast. Reconstr. Surg., 18: 460-468, 1956.

9- Bauer T.B., Tondra J.M. and Trusler H.M.: Technical modification in repair of syndactylism. Plast. Reconstr. Surg., 17: 385-92, 1956.

10- Flatt A.E.: Treatment of syndactylism. Plast. Reconstr. Surg., 29: 336-41, 1962.

11- Brown P.M.: Syndactyly-A Review and Long-Term Results. Hand, os-9 (1): 16-27, 1977.

12- Toledo L.C. and Ger E.: Evaluation of the operative treatment of syndactyly. The Journal of Hand Surgery, 4 (6): 556-564, 1979.

13- Niranjan N.S. and De Carpentier J.: A new technique for the division of syndactyly. Eur. J. Plast. Surg., 13 (3): 101-104, 1990
14- Ekerot L.: Syndactyly correction without skin-grafting. J. Hand Surg. [Br.], 21 (3): 330-337, 1996.

15- Vickers D. and Donnelly W.: Corrective surgery of syndactyly without the use of skin grafts. Hand Surg., 1: 203208, 1996.

16- Sherif M.M.: V-Y dorsal metacarpal flap: A new technique for the correction of syndactyly without skin graft. Plast. Reconstr. Surg., 101 (7): 1861-6, 1998.

17- Sharma R.K., Tuli P., Makkar S.S. and Parashar A.: Endof-skin grafts in syndactyly release: Description of a new flap for web space resurfacing and primary closure of finger defects. Hand (NY), 4 (1): 29-34, 2009.

18- Aydın A. and Ozden B.C.: Dorsal Metacarpal Island Flap in Syndactyly Treatment. Ann. Plast. Surg., 52: 43-48, 2004.

19- Yildirim C., Sentürk S., Keklikçi K. and Akmaz I.: Correction of syndactyly using a dorsal separated V-Y advancement flap and a volar triangular flap in adults. Ann. Plast. Surg., 67: 357-63, 2011.

20- Matsumine H., Yoshinaga Y., Fujiwara O., Sasaki R., Takeuchi M. and Sakurai H.: Improved "bell-bottom" flap surgical technique for syndactyly without skin graft. Plast. Reconstr. Surg., 128 (5): 504e-509e, 2011.

21- Teoh L.C. and Lee J.Y.: Dorsal pentagonal island flap: A technique of web reconstruction for syndactyly that facilitates direct closure. Hand Surg., 9: 245-52, 2004.

22- Wafa A.M.: Hourglass dorsal metacarpal island flap: A new design for syndactylized web reconstruction. J. Hand Surg. Am., 33 (6): 905-8, 2008.

23- Hsu V.M., Smartt J.M. Jr. and Chang B.: The modified V-Y dorsal metacarpal flap for repair of syndactyly without skin graft. Plast. Reconstr. Surg., 125 (1): 225-232, 2010.

24- Liu J., Zheng H., Chen Z., Dai X., Schilling A.F. and Machens H-G.: Dorsal plane shaped advancement flap for the reconstruction of web space in syndactyly without skin grafting: A preliminary report, J. Plast. Reconstr. Aesthet. Surg., Nov., 68 (11): e167-73, 2015.

25- Greuse M. and Coessens B.C.: Congenital syndactyly: Defatting facilitates closure without skin graft. J. Hand Surg. (Am.), 26: 589-594, 2001.

26- Quaba A.A. and Davison P.M.: The distally based dorsal hand flap. Br. J. Plast. Surg., 43: 28-39, 1990.

27- Yuan F1, Zhong L. and Chung K.C.: Aesthetic Comparison of Two Different Types of Web-Space Reconstruction for Finger Syndactyly. Plast. Reconstr. Surg., 142 (4): 963971, 2018.

28- Sullivan M.A. and Adkinson J.M.: A systematic review and comparison of outcomes following simple syndactyly reconstruction with skin grafts or a dorsal metacarpal advancement flap. J. Hand Surg. Am., 42: 34-40, 2017. 